\title{
Comparison of Contemporary Drug-eluting Coronary Stents - Is Any Stent Better than the Others?
}

\author{
William Parker ${ }^{1,2}$ and Javaid Iqbal $\left.\right|^{1,2}$ \\ 1. Sheffield Teaching Hospitals NHS Foundation Trust, Sheffield, UK; 2. Department of Infection, Immunity and Cardiovascular Disease, \\ University of Sheffield, Sheffield, UK.
}

DOI: https://doi.org/10.17925/HI.2020.14.1.34

$\mathrm{P}$ ercutaneous coronary intervention (PCl) with implantation of a metallic drug-eluting stent (DES) is the mainstay of treatment in patients with significant coronary artery disease or acute coronary syndromes. DESs comprise a metallic platform and an anti-proliferative drug, usually released from a polymer coating. A wide range of DESs, differing in platform, polymer or drug, are currently available for clinical use. Although there are significant differences in the physical, biological and pharmacological properties of contemporary DESs, it remains unclear whether these impact meaningfully on clinical outcomes for patients undergoing PCI. Numerous randomised clinical trials have compared DESs in recent years, but these trials are typically designed to show non-inferiority, rather than superiority. Data from meta-analyses have helped to study this in larger populations, but have limitations. Improvement in stent design continues and ongoing work is exploring the effects of new innovations as well as gathering further data on existing devices. This review explores the development, properties and clinical efficacy of current-generation DESS, comparing different types where possible, whilst identifying areas of further work.

\section{Keywords}

Stents, antiproliferative drugs,

biodegradable, polymers, bioresorbable

Disclosures: William Parker and Javaid Iqbal have no financial or non-financial relationships or activities to declare in relation to this article. Review Process: Double-blind peer review. Compliance with Ethics: This article involves a review of the literature and did not involve any studies with human or animal subjects performed by either of the authors.

Authorship: The named authors meet the International Committee of Medical Journal Editors (ICMJE) criteria for authorship for this manuscript, take responsibility for the integrity of the work as a whole and have given final approval for the version to be published.

Access: The article is freely accessible at

touchCARDIO.com (c) Touch Medical Media 2020.

Received: 13 October 2019

Accepted: 9 March 2020

Published Online: 18 June 2020

Citation: Heart International. 2020;14(1):34-42

Corresponding Author: Javaid Iqbal,

South Yorkshire Cardiothoracic Centre,

Sheffield Teaching Hospitals NHS Foundation Trust,

Sheffield S5 7AU, UK.

E: javaid@doctors.net.uk

Support: No funding was received in

the publication of this article.
Coronary artery disease (CAD), due to development of atherosclerotic plaques, remains a leading cause of morbidity and mortality. If unstable or clinically significant, these are frequently treated with percutaneous coronary intervention (PCl), typically involving balloon angioplasty and implantation of a metallic drug-eluting stent (DES). ${ }^{1}$ Coronary stents have substantially evolved since their first use in the 1980s due to continuous work to refine their design, structure and materials. A number of DESS, differing in design and composition, are currently available for clinical use and are summarised in Figure 1. The manufacture and sale of DESs has become a large industry, with the market expected to be worth up to US $\$ 17$ billion by $2025 .{ }^{2}$ In $2013,>75 \%$ of the global DES market share (sampled in the 10 major markets) was held by three companies: Abbott Vascular (Chicago, IL, USA; manufacturer of, for example, XIENCE ${ }^{\circledR}$ Stents), Boston Scientific (Marlborough, MA, USA; e.g., Promus ${ }^{\circledR}$ ) and Medtronic (Dublin, Ireland; e.g., Resolute ${ }^{\circledR}$ ). The market continues to develop, with particular expansion occurring in Asia and more expected in the coming years. ${ }^{3}$ Emerging manufacturers, for example in China, are predicted to challenge current dominance. ${ }^{4}$ The choice of a stent for a particular patient and coronary lesion, however, largely remains the operator's choice. This article reviews the structure, design and clinical data of commonly-used contemporary DESs to identify the differences and whether any particular stent performs better than others.

\section{Evolution of drug-eluting stents}

\section{Early years of angioplasty and bare metal stents}

Coronary angioplasty was first performed by Andreas Gruentzig in $1977 .{ }^{5}$ Initially, angioplasty was performed without stent deployment; however, its efficacy was reduced by acute closure or restenosis. Coronary stents were developed to overcome these shortcomings. ${ }^{6}$ The vast majority of $\mathrm{PCl}$ procedures performed currently involve angioplasty with stent deployment. Wallstent ${ }^{\mathrm{T} M}$, (Schneider AG, Bulach, Switzerland), a 'self-expanding, elastic, macroporous tubular prosthesis, woven from stainless steel', was the first stent implanted in a human coronary artery in 1984 by Sigwart and colleagues.? In 1987, Schatz and co-workers developed the first stent to obtain US Food and Drug Administration approval (Palmaz-Schatz ${ }^{\oplus}$; Johnson \& Johnson, New Brunswick, NJ, USA). This was the first balloon-expandable, stainless-steel, tubular stent, and was widely used throughout the 1990s. In the early years of that decade, a number of other stents became available, including FlexStent ${ }^{\circledR}$ (Cook, Bloomington, IN, USA), Wiktor ${ }^{\circledast}$ (Medtronic, Minneapolis, MN, USA), Micro ${ }^{\circledR}$ (Applied Vascular Engineering, Twickenham, UK), Cordis $^{\oplus}$ (Cordis, Santa Clara, CA, USA) and MULTI-LINK ${ }^{\circledast}$ (Advanced Cardiovascular Systems, Santa Clara, CA, USA). ${ }^{6}$

These bare metal stents (BMSs) reduced acute vessel closure and early elastic recoil; however, they were bulky, difficult to use and associated with frequent device failure. 
Figure 1: Examples of currently available permutations of stent platform, polymer type and eluted drug

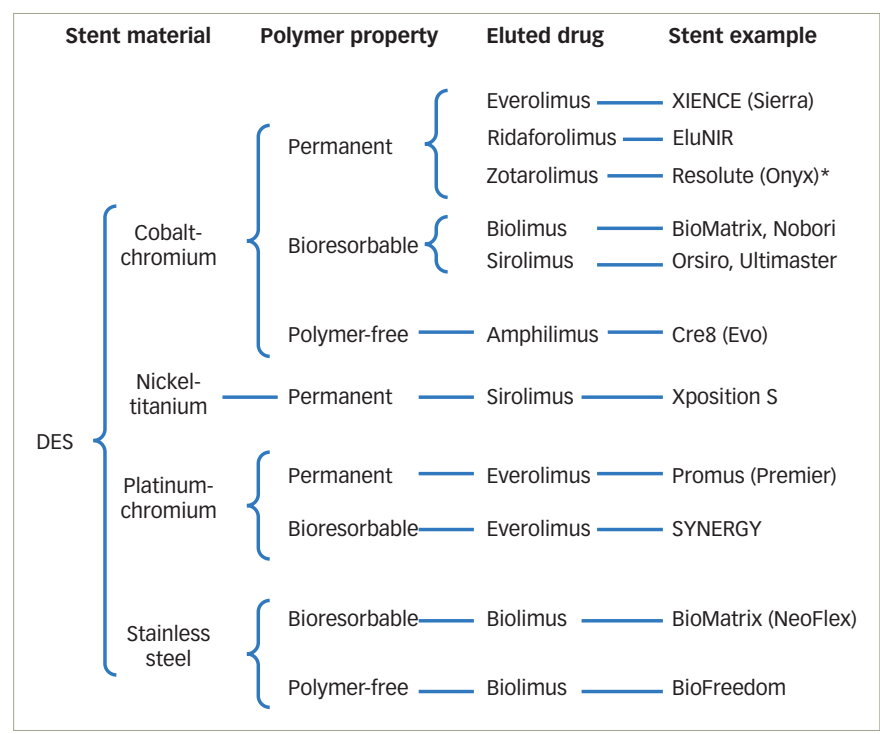

*Cobalt-chromium outer shell with a platinum-iridium core. $D E S=$ drug-eluting stent.

Furthermore, the risk of in-stent restenosis was significant due to proliferation and migration of vascular smooth muscle cells within the device. ${ }^{8}$ The use of stents, therefore, remained limited to cases of acute/threatened closure or restenosis after balloon angioplasty until two landmark trials, the Belgium Netherlands Stent Arterial Revascularization Therapies Study (BENESTENT) and the North American Stent Restenosis Study (STRESS), showed superiority of BMSS over balloon angioplasty. ${ }^{910}$ However, the incidence of in-stent restenosis remained as high as $20-30 \%$.

\section{Development of drug-eluting stents}

coating stents with anti-proliferative drugs, e.g., sirolimus or paclitaxel, substantially reduced in-stent restenosis. ${ }^{11,12}$ When incorporated within a polymer and coated on the surface of BMSs, these were released slowly over a few weeks after deployment. Eduardo Sousa implanted the first sirolimus-eluting stent in 1999 and it became available for clinical use as the CYPHER ${ }^{\text {TM }}$ (Cordis) stent in 2002. CYPHER was tested in numerous randomised controlled trials (RCTs), demonstrating a significant reduction in in-stent restenosis and target vessel revascularisation (TVR) compared with BMSS. ${ }^{11}$ TAXUS ${ }^{\circledast}$ (Boston Scientific), a paclitaxel-eluting stent, closely followed CYPHER, and again many RCTS (TAXUS I-IV) confirmed its efficacy against BMSs. ${ }^{12,13}$ Early-generation DESs, however, were linked with risk of stent thrombosis, possibly due to delayed endothelialisation by the anti-restenotic drugs or delayed hypersensitivity reaction to the polymer in DESS. ${ }^{14,15}$ The concerns of stent thrombosis with early-generation DESS stimulated development of novel anti-platelet agents, better polymers, and newer generation of DESS.

\section{Components of a drug-eluting stent}

There are three major components of a DES: the metallic platform, polymer (if present) and anti-proliferative drug. Examples and properties of currently-available stents with different permutations of this construction are shown in Table 1.

\section{Metallic platform}

First-generation stents were typically made of stainless steel as it provides adequate radial strength to restore the patency of a stenotic artery. Although stainless steel remains a material used in some current-generation DESS (e.g., BioFreedom ${ }^{\mathrm{TM}}$, BioMatrix ${ }^{\mathrm{TM}}$ [Biosensors International, Singapore], Nobori ${ }^{\circledast}$ [Terumo, Tokyo, Japan]), alloys are more commonly employed. These include cobalt-chromium (e.g., XIENCE and Ultimaster ${ }^{\mathrm{TM}}$ [Terumo]), platinum-chromium (e.g., Promus and SYNERGYTM [Boston Scientific]) and nickel-titanium (also known as nitinol e.g., Xposition S [Stentys, Paris, France]). Some stents include two alloys, for example the Resolute Onyx ${ }^{\mathrm{TM}}$ (Medtronic) stent has an outer shell of a cobalt-based alloy, but a platinum-iridium core in order to increase radiopacity. ${ }^{16}$ Physical properties of commonly-used materials for metallic DES platforms are summarised in Table 2. Compared to stainless steel, these alloys have intrinsically greater tensile strength whilst possessing similar or reduced elasticity. This allows manufacturing of thinner struts (typically $>100 \mu \mathrm{m}$ for stainless steel versus $<100 \mu \mathrm{m}$ for alloys) whilst maintaining strength, improving flexibility and deliverability, and reducing risk of stent thrombosis. Strut thickness and stent flexibility have an impact on the degree of injury, risk of rupture of the elastic laminae and overall inflammation, which may increase the risk of stent thrombosis events post-implantation. In addition, first-generation DES studies showed that thicker struts were associated with a higher incidence of side branch occlusion compared with thinner-strut DESS. ${ }^{17}$ Moreover, thinner-strut devices have been associated with better clinical outcomes. ${ }^{18}$

\section{Polymers}

In first-generation DESS, the drug was incorporated in permanent (i.e., non-biodegradable) synthetic polymers such as polyethylene-co-vinyl acetate, poly-n-butyl methacrylate, and the tri-block copolymer poly(styrene-b-isobutylene-b-styrene). Histopathological data indicated that the delayed vascular healing due to these polymer coatings may be associated with an increased risk of very late stent thrombosis after first-generation DES implantation. ${ }^{6}$ These polymers were superseded by more biocompatible permanent polymers (PPS) such as phosphorylcholine and a co-polymer of poly-vinylidene fluoride and hexafluoropropylene. Further development of DESs has led to those with biodegradable polymers, the rationale for these being that they behave as a conventional DES in the early phase and, once all the drug has been released and the polymer degraded, revert to a BMS as only the metallic platform remains. These typically utilise polylactic acid or a variation thereof as the polymer, which is broken down by hydrolysis over a period of months to lactic acid. Most recently, polymer-free DESs have come onto the market. Instead of utilising a polymer to contain and release the drug, this is directly applied to the metallic surface of the DES in micropores. These have the obvious theoretical advantage of avoiding polymer-related complications altogether.

\section{Anti-proliferative drugs}

Amongst a variety of immunosuppressive and anti-proliferative agents tested to-date, mammalian target of rapamycin inhibitors have prevailed. Contemporary stents are mostly sirolimus-eluting stents, everolimus-eluting stents, zotarolimus-eluting stents or biolimus-eluting stents. Characteristics of these four commonly-used anti-proliferative drugs are shown in Table 3. However, the search for a better drug continues, and other drugs, including novolimus and myolimus, are being tested. ${ }^{19}$

\section{Comparative data for contemporary drug-eluting stents} Stent platform and strut thickness

cobalt-chromium and platinum-chromium stents have been tested against current-generation stainless-steel stents. The COMPARE-II trial (ClinicalTrials.gov identifier: NCT01233453) examined the Nobori stainless-steel biolimus-eluting stent against the XIENCE cobalt-chromium everolimus-eluting stent and the Promus 
Table 1: Examples of current-generation drug-eluting stents and their physical properties

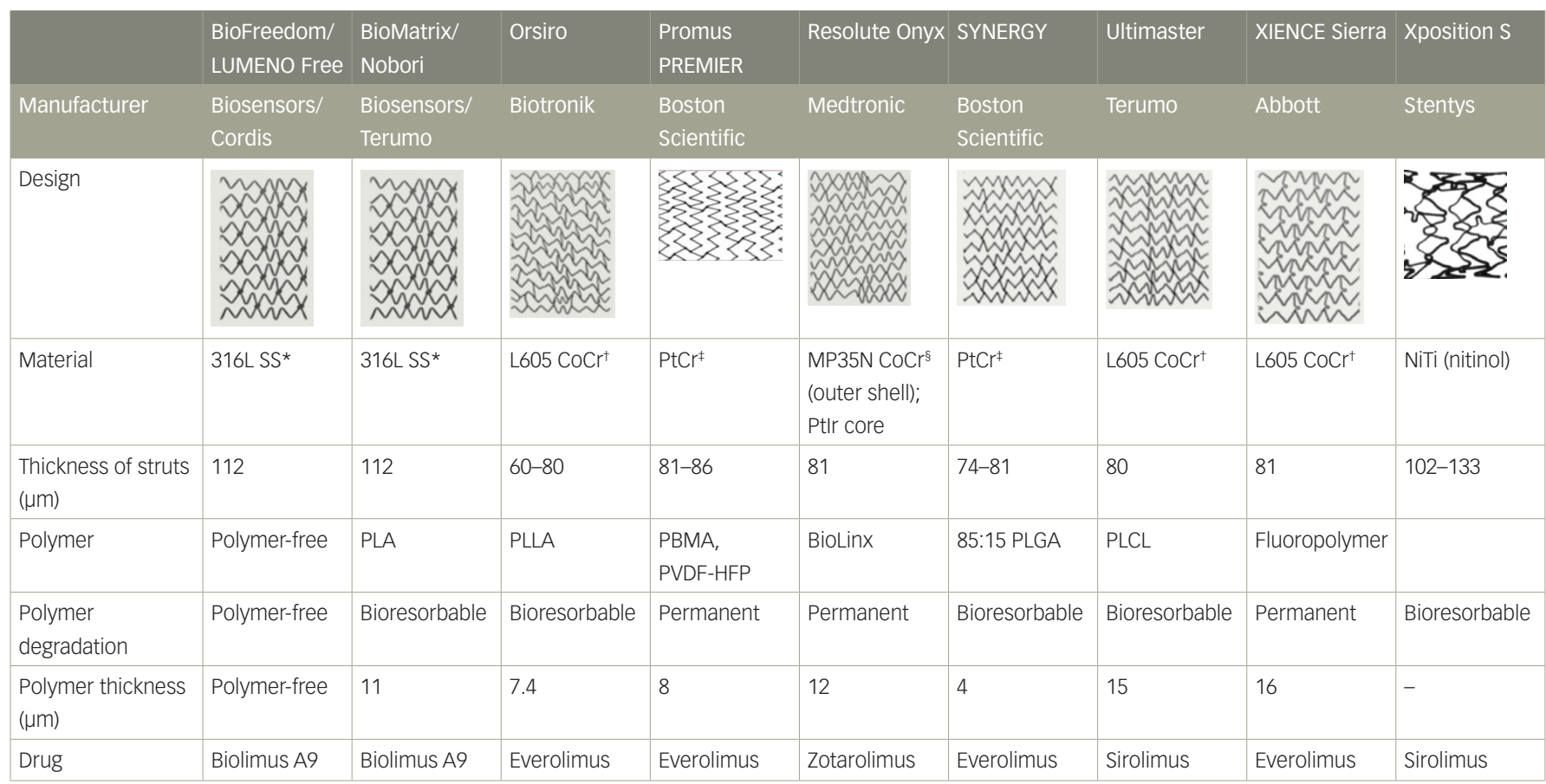

*316L SS: 64\% iron, 18\% chromium, 14\% nickel, 2.6\% molybdenum, 2\% (max) manganese.

+ L605 CoCr: 52\% cobalt, 20\% chromium, 15\% tungsten, 10\% nickel, 3\% (max) iron, 1.5\% (max) manganese.

₹PtCr: $37 \%$ iron, 33\% platinum, 18\% chromium, 9\% nickel, 2.6\% molybdenum, $0.05 \%$ (max) manganese.

${ }^{3}$ MP35N CoCr: 35\% nickel, 34\% cobalt, 20\% chromium 9.75\% molybdenum, 1\% (max) iron, 1\% (max) titanium, 0.15\% (max) manganese.

$\mathrm{COCr}=$ cobalt-chromium: HFP = hexafluoropropylene: NiTi $=$ nickel-titanium: $P L A=$ polylactic acid $\cdot P L C L=$ poly $(D, L-l a c t i d e-c o-c a p r o l a c t o n e) \cdot P L G A=$ poly $(D, L-l a c t i d e-c o-$

glycolide); PLLA = poly-L-lactic acid; PBMA = poly ( $n$-butyl methacrylate); PtCr = platinum-chromium; PtIr = platinum-iridium; PVDF = polyvinylidene fluoride; SS = stainless steel.

Table 2: Physical properties of materials used for coronary metallic stent platforms

\begin{tabular}{|l|l|l|l|l|}
\hline Material & $\begin{array}{l}\text { Tensile } \\
\text { strength } \\
\text { (MPa) }\end{array}$ & $\begin{array}{l}\text { Tensile } \\
\text { elasticity } \\
\text { (GPa) }\end{array}$ & $\begin{array}{l}\text { Elongation at } \\
\text { break (\%) }\end{array}$ & $\begin{array}{l}\text { Degradation } \\
\text { time } \\
\text { (months) }\end{array}$ \\
\hline 316L stainless steel & 668 & 193 & $>40$ & Biostable \\
\hline Nitinol (nickel-titanium) & 700 & 45 & $10-20$ & Biostable \\
\hline L605 cobalt chromium & 1,000 & 243 & 40 & Biostable \\
\hline MP35N cobalt chromium & 930 & 233 & 65 & Biostable \\
\hline Platinum chromium & 834 & 203 & 45 & Biostable \\
\hline
\end{tabular}

GPa = gigapascal; $\mathrm{MPa}=$ megapascal.

platinum-chromium everolimus-eluting stent. There were no significant differences in the primary composite endpoint of safety (cardiac death and non-fatal myocardial infarction [MI]) and efficacy (clinically indicated TVR) at 12 months. ${ }^{20}$ Similarly, no differences in clinical outcomes were seen in the NEXT trial comparing Nobori versus XIENCE/Promus. ${ }^{21}$ After 5 years, the stent thrombosis rate was $0.49 \%$ versus $0.34 \%$ for the Nobori and the XIENCE/Promus, respectively $(p=0.52) .{ }^{22}$

Current generations of stainless-steel stents have also been tested against a reference group receiving only platinum-chromium stents. For example, in the SORT-OUT VIII trial (NCT02093845), the BioMatrix stainless-steel biolimus-eluting stent was compared with the SYNERGY platinum-chromium everolimus-eluting stent. The primary endpoint of target lesion failure (TLF) at 1 year occurred in $4.0 \%$ (platinum-chromium) versus $4.4 \%$ (stainless steel), (non-inferiority p<0.001).23 The EVERBIO-II trial (NCT01711931) compared 80 patients implanted with the platinum-chromium everolimus-eluting stent
Table 3: Chemical and pharmacological properties of anti-proliferative agents commonly-utilised in drug-eluting stents

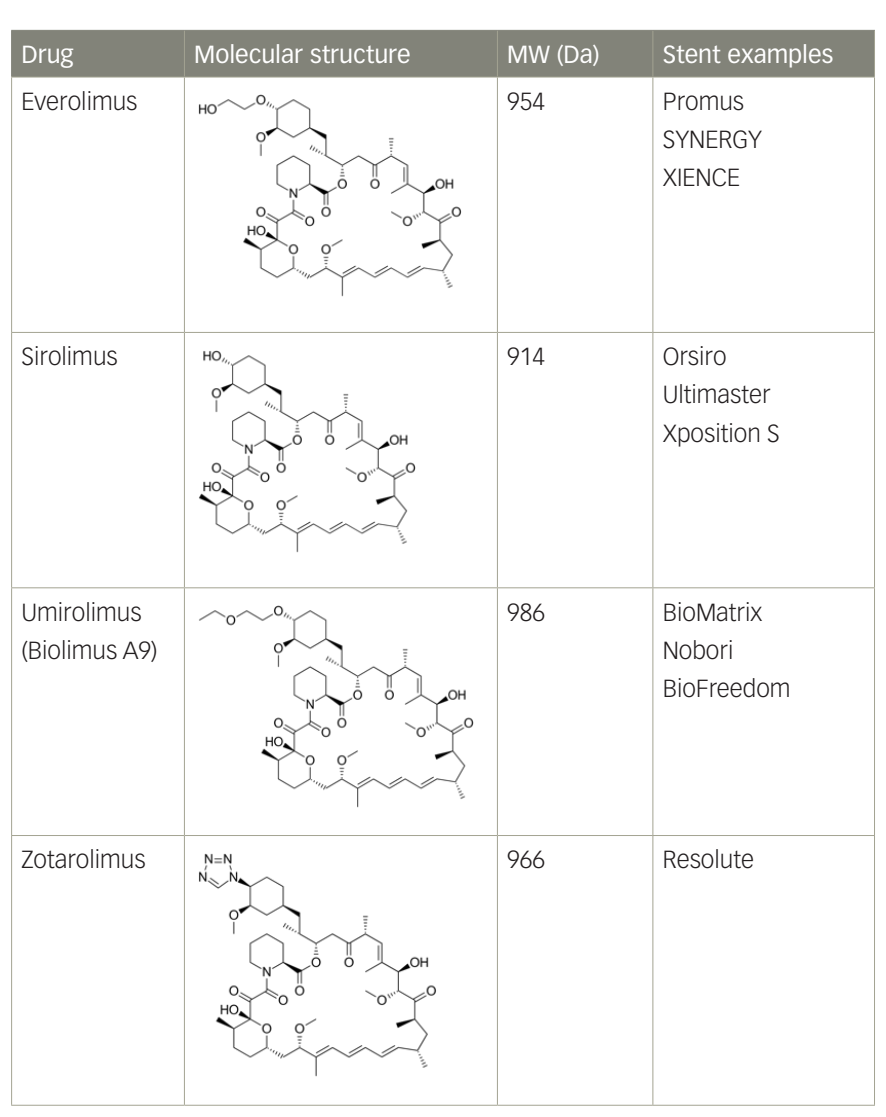

$D a=$ Daltons; $M W=$ molecular weight. 
(PROMUS) and 80 with BioMatrix stents and found no difference in late lumen loss at 9 months (platinum-chromium $0.24 \pm 0.32 \mathrm{~mm}$ versus stainless steel $0.25 \pm 0.41 \mathrm{~mm}){ }^{24}$

Platinum-chromium stents have similarly been assessed against cobalt-chromium stents. For example, the PLATINUM programme of studies tested Promus stents (platinum-chromium everolimus-eluting stents) against XIENCE stents (cobalt-chromium everolimus-eluting stents). In the PLATINUM study (NCT00823212), which excluded those undergoing $\mathrm{PCl}$ for $\mathrm{MI}$, TLF at 5 years was 9.1\% versus 9.3\% (hazard ratio [HR] $0.97, p=0.87$ ). Similarly, there was little difference in stent thrombosis rates $(0.8 \%$ versus $0.7 \%, p=0.79) .{ }^{25}$ PLATINUM + (Trial to assess the everolimus-eluting coronary stent system (PROMUS Element) for coronary revascularization; NCT01342822), which was an all-comers study, showed that target vessel failure was $4.6 \%$ versus $3.2 \%$ (non-inferiority $p=0.012$, superiority $p=0.08$ ). ${ }^{26}$ Although there were no significant differences in the rates of cardiac death, ischaemia-driven target lesion revascularisation or $\mathrm{Ml}$, there did appear to be a nominal difference in the latter ( $1.6 \%$ versus $0.8 \%, p=0.09)$.

Stent mal-expansion and mal-apposition can be another problem with balloon-expandable stents. ${ }^{27} \mathrm{~A}$ nickel-titanium platform has been used to manufacture self-apposing stents, for example, the Xposition-S (Stentys). This facilitates better contouring of the stent to the vessel wall, especially useful in the tapering vessels. Earlier studies have been promising, but further trials are warranted to define the use of this platform amongst current-generation DESS. ${ }^{28}$

Given that the main advantage of alloys over stainless steel is in allowing thinner struts whilst maintaining structural integrity, other analyses have sought to determine whether strut thickness itself has a significant effect on outcomes. Recent meta-analyses have demonstrated the benefits of devices with reduced strut thickness. lantorno and colleagues combined the results of 69 trials $(n=80,885)$ and divided these into ultrathin, thin, intermediate and thick strut devices. Compared with thick-strut DESs, those with ultrathin struts had significantly less stent thrombosis and $\mathrm{Ml}$ (odds ratio [OR] 0.43, 95\% confidence interval [Cl] 0.27-0.68; and OR $0.73,95 \% \mathrm{Cl} 0.62-0.92$, respectively)..$^{18}$ This was consistent with another, smaller, meta-analysis of 10 trials $(n=11,658)$, focusing on newer-generation stents and demonstrating that ultrathin strut DESS were associated with lower rates of stent thrombosis (risk ratio [RR] $0.72,95 \% \mathrm{Cl}$ 0.51-1.01). ${ }^{29}$ Hence, it would be reasonable to conclude that stents with thinner struts (i.e., those made with cobalt-chromium or platinum-chromium alloys) are better than those with thicker struts, but that within current-generation DESs, choice of material itself does not appear to be a factor in determining clinical outcomes.

\section{Polymers}

Several studies have evaluated current-generation DESs with permanent polymer (PP) versus bioresorbable polymer (BP) coatings (Table 4). ${ }^{20,21,30-3}$ Whilst powered for, and typically demonstrating, non-inferiority, these studies have generally failed to show superiority of one stent type over another. Of note, however, the BIOFLOW-V trial (NCT02389946), which compared a cobalt-chromium BP sirolimus-eluting stent (Orsiro ${ }^{\circledR}$, Biotronik, Berlin, Germany) against a cobalt-chromium PP everolimus-eluting stent (XIENCE), demonstrated superiority in terms of TLF at 12 months, driven by a lower rate of target vessel $\mathrm{Ml}(5 \%$ versus $8 \%, \mathrm{p}=0.016){ }^{30}$ However, a direct comparison of a platinum-chromium everolimus-eluting stent with BP (SYNERGY) or PP (Promus) in the EVOLVE-II study (NCT01665053) showed non-inferiority, but no evidence of superiority and in fact, the rate of TLF at 12 months was numerically greater in the BP group. ${ }^{35}$
On the other hand, the SORT-OUT V trial (NCT01254981), comparing stainless-steel biolimus-eluting stent with BP (Nobori) versus a first-generation stainless-steel sirolimus-eluting stent with PP (CYPHER), narrowly failed to show non-inferiority in the pre-specified intention-to-treat analysis of the primary composite endpoint of safety (cardiac death, MI, definite stent thrombosis) and efficacy (TVR) at 9 months. ${ }^{37}$ Other studies of the Nobori versus PP non-stainless steel everolimus-eluting stent, whilst demonstrating non-inferiority, have shown a similar or nominally greater incidence of the study primary endpoints, and also of stent thrombosis, in those receiving the BP DES. This pattern was not replicated, however, in the SORT-OUT VI trial (NCT01956448) of the BioMatrix BP biolimus-eluting stent, of very similar design to Nobori, versus a cobalt-chromium zotarolimus-eluting stent with PP (Resolute) nor versus CYPHER in LEADERS (NCT00389220), which suggested nominal, but not significant, advantages of the BioMatrix device. ${ }^{36,38}$

One could argue that given the cobalt-chromium/platinum-chromium DESS with BP have consistently shown non-inferiority or superiority to those with $\mathrm{PP}$, and there may be a signal of disadvantage with regards to the stainless-steel BP DESs, that the former should be preferred over the latter. This may be due to differences in strut thickness (e.g., Nobori $112 \mu \mathrm{m}$, Orsiro 60-80 $\mu \mathrm{m}$ ), although Nobori appeared to perform worst when tested against a stainless-steel PP sirolimus-eluting stent of even greater strut thickness. ${ }^{37}$

Within the BP DES group, a limited number of studies have compared these head-to-head. The SORT-OUT VII trial (NCT01879358) tested Orsiro versus Nobori and found no significant difference in the primary endpoint of cardiac death, target lesion-related $\mathrm{Ml}$ or target lesion revascularisation within 1 year, but this was numerically higher in the Nobori arm (4.6\% versus $3.8 \%$ ) and was accompanied by a significantly greater incidence of definite stent thrombosis $(1.2 \%$ versus $0.4 \%$, $\mathrm{p}=0.03$ ). ${ }^{39}$ The SORT-OUT VIII trial (NCT02093845) tested the platinum-chromium BP everolimus-eluting stent (SYNERGY) against the stainless-steel BP biolimus-eluting stent (BioMatrix) and found, once again, no significant difference in TLF but a numerical advantage of the SYNERGY device (4.0\% versus $4.4 \%)$. $^{23}$ These data could be interpreted to suggest that if using a BP DES, stainless-steel devices may have disadvantages over newer alloy BP DESS.

Helpfully, several meta-analyses addressing this issue have now been published. For example, El-Hayek et al. studied 16 RCTs including 19,886 patients who had received either BP DESs or newer variants of PP DESs, followed up for a mean of 26 months. ${ }^{40}$ They concluded there were no significant differences in TVR, stent thrombosis or other clinical outcomes between the two types. This finding was not affected by stent material, eluted drug or strut thickness. Furthermore, a landmark analysis, performed to study very late stent thrombosis, which is hypothetically reduced by use of BP DESS over PP DESS, showed no significant difference (RR 0.87, 95\% Cl 0.49-1.53, $\mathrm{p}=0.62$ ). Conversely, Kobayashi and colleagues pooled data from nine trials $(n=4,458)$ but with a longer mean follow-up of 63 months. ${ }^{41}$ Comparing thin-strut BP DESS with durable polymer (DP) DESS; although there was no discernible difference in TLF (OR 1.04, 95\% Cl 0.89-1.21), there was a nominally reduced rate of definite/probable stent thrombosis in the BP DES group $(0.78,95 \% \mathrm{Cl}$ 0.59-1.01). Overall, long-term outcomes do not appear to be different between current DESs with DP and BP properties, likely due to improved biocompatibility of polymers in current-generation DESs.

Considering the polymer-free DESS currently available, there are limited data from RCTs comparing these with other DESs. A small study (NEXT, 
Table 4: Examples of studies comparing drug-eluting stents with bioresorbable polymer versus permanent polymer coating

\begin{tabular}{|c|c|c|c|c|c|c|c|c|c|c|c|}
\hline Study & Year & $\begin{array}{l}\text { BP-DES } \\
\text { tested }\end{array}$ & Metal & Drug & PP-DES & Metal & Drug & $n$ & Primary endpoint & $\begin{array}{l}\text { Result } \\
\text { (BP- versus PP-DES) }\end{array}$ & $\begin{array}{l}\text { Stent thrombosis } \\
\text { (definite, } 9 \text { or } 12 \\
\text { months) }\end{array}$ \\
\hline $\begin{array}{l}\text { BIOFLOW V } 30 \\
\text { (NCT02389946) }\end{array}$ & 2017 & Orsiro & $\mathrm{CoCr}$ & S & XIENCE & $\mathrm{CoCr}$ & E & 1,334 & TLF at 12 months & $\begin{array}{l}6 \% \text { versus } 10 \% \\
(p=0.04)\end{array}$ & $\begin{array}{l}0.48 \% \text { versus } 0.71 \%, \\
p=0.69\end{array}$ \\
\hline $\begin{array}{l}\text { BIONYX }{ }^{31} \\
\text { (NCT02508714) }\end{array}$ & 2018 & Orsiro & $\mathrm{CoCr}$ & S & Resolute & $\mathrm{CoCr}$ & Z & 2,488 & TVF at 12 months & $\begin{array}{l}4.7 \% \text { versus } 4.5 \% \text {, } \\
p=0.0005^{*}, p=0.77 \\
\text { (superiority) }\end{array}$ & $\begin{array}{l}0.6 \% \text { versus } 0.1 \%, \\
p=0.0334\end{array}$ \\
\hline $\begin{array}{l}\text { BIO-RESORT }{ }^{32} \\
\text { (NCT01674803) }\end{array}$ & 2016 & $\begin{array}{l}\text { SYNERGY/ } \\
\text { Orsiro }\end{array}$ & $\begin{array}{l}\mathrm{PtCr} / \\
\mathrm{CoCr}\end{array}$ & $E / S$ & Resolute & $\mathrm{CoCr}$ & z & 3,514 & TVF at 12 months & $\begin{array}{l}5 \% \text { (EES) versus } \\
5 \% \text { (SES) versus } 5 \% \\
\text { (ZES); EES versus ZES } \\
p=0.45, \text { SES versus } \\
\text { ZES } p=0.46\end{array}$ & $\begin{array}{l}0.34 \% \text { versus } 0.34 \% \\
\text { versus } 0.26 \%, p=0.70 \\
\text { (EES versus ZES), } \\
p=0.70 \text { (SES versus } \\
\text { ZES) }\end{array}$ \\
\hline $\begin{array}{l}\text { BIOSCIENCE }{ }^{33} \\
\text { (NCT01443104) }\end{array}$ & 2014 & Orsiro & $\mathrm{CoCr}$ & S & XIENCE & $\mathrm{CoCr}$ & E & 2,119 & TLF at 12 months & $\begin{array}{l}6.7 \% \text { versus } 6.7 \%, \\
p=0.950\end{array}$ & $\begin{array}{l}2.0 \% \text { versus } 3.0 \%, \\
p=0.16\end{array}$ \\
\hline $\begin{array}{l}\text { CENTURY } \|^{34} \\
\text { (UMINO00006940) }\end{array}$ & 2014 & Ultimaster & $\mathrm{CoCr}$ & S & XIENCE & $\mathrm{CoCr}$ & E & 1,123 & $\begin{array}{l}\text { Freedom from TLF at } \\
9 \text { months }\end{array}$ & $\begin{array}{l}95.6 \% \text { versus } 95.1 \% \\
p<0.0001^{*}\end{array}$ & $\begin{array}{l}0.91 \% \text { versus } 0.91 \% \text {, } \\
p=0.99\end{array}$ \\
\hline $\begin{array}{l}\text { COMPARE-1120 } \\
\text { (NCT01233453) }\end{array}$ & 2013 & Nobori & SS & B & $\begin{array}{l}\text { XIENCE/ } \\
\text { Promus }\end{array}$ & $\begin{array}{l}\mathrm{CoCr} / \\
\mathrm{PtCr}\end{array}$ & $E$ & 2,707 & $\begin{array}{l}\text { Composite of cardiac } \\
\text { death, Ml and } \\
\text { clinically indicated } \\
\text { TVR at } 12 \text { months }\end{array}$ & $\begin{array}{l}5.2 \% \text { versus } 4.8 \%, \\
p<0.0001^{*}\end{array}$ & $\begin{array}{l}0.7 \% \text { versus } 0.4 \% \\
p=0.38\end{array}$ \\
\hline $\begin{array}{l}\text { EVOLVE } \|^{35} \\
\text { (NCT01665053) }\end{array}$ & 2015 & SYNERGY & PtCr & E & Promus & PtCr & E & 1,684 & TLF at 12 months & $\begin{array}{l}6.7 \% \text { versus } 6.5 \%, \\
p=0.0005^{*}\end{array}$ & $\begin{array}{l}0.2 \% \text { versus } 0.2 \%, \\
p>0.99\end{array}$ \\
\hline $\begin{array}{l}\text { LEADERS }^{36} \\
\text { (NCT00389220) }\end{array}$ & 2008 & BioMatrix & SS & B & CYPHER & SS & $S$ & 1,707 & $\begin{array}{l}\text { Cardiac death, MI and } \\
\text { TVR at } 9 \text { months }\end{array}$ & $\begin{array}{l}9.2 \% \text { versus } 10.5 \% \text {, } \\
p=0.39\end{array}$ & $\begin{array}{l}1.9 \% \text { versus } 2.0 \%, \\
p=0.84\end{array}$ \\
\hline $\begin{array}{l}\text { NEXT21 } \\
\text { (NCT01303640) }\end{array}$ & 2013 & Nobori & SS & B & $\begin{array}{l}\text { XIENCE/ } \\
\text { Promus }\end{array}$ & $\begin{array}{l}\mathrm{CoCr} / \\
\mathrm{PtCr}\end{array}$ & E & 3,235 & TLR at 12 months & $\begin{array}{l}4.2 \% \text { versus } 4.2 \% \text {, } \\
p<0.0001^{*}, p=0.93 \\
\text { (superiority) }\end{array}$ & $\begin{array}{l}0.25 \% \text { versus } 0.06 \%, \\
p=0.18\end{array}$ \\
\hline $\begin{array}{l}\text { SORT-OUT V }{ }^{37} \\
\text { (NCT01254981) }\end{array}$ & 2013 & Nobori & SS & B & CYPHER & SS & S & 1,229 & $\begin{array}{l}\text { Composite of safety } \\
\text { (cardiac death, MI, } \\
\text { definite ST) and } \\
\text { efficacy (TVR) at } \\
9 \text { months }\end{array}$ & $\begin{array}{l}4.1 \% \text { versus } 3.1 \% \text {, } \\
p=0.06^{*}\end{array}$ & $\begin{array}{l}0.7 \% \text { versus } 0.2 \%, \\
p=0.034\end{array}$ \\
\hline $\begin{array}{l}\text { SORT-OUT V|38 } \\
\text { (NCT01956448) }\end{array}$ & 2015 & BioMatrix & SS & B & Resolute & $\mathrm{COCr}$ & Z & 1,502 & TLF at 12 months & $\begin{array}{l}5.0 \% \text { versus } 5.3 \% \\
p=0.004^{*}\end{array}$ & $\begin{array}{l}0.4 \% \text { versus } 0.6 \% \text {, } \\
p=0.44\end{array}$ \\
\hline
\end{tabular}

*Non-inferiority analysis.

$B=$ biolimus; $B P=$ bioresorbable polymer; CoCr = cobalt-chromium; $D E S=$ drug-eluting stent; $E$ = everolimus; $E$ ES = everolimus-eluting stent; $M I=$ myocardial infarction; $P P=$ permanent polymer; PtCr = platinum-chromium; $S$ = sirolimuS; SES = sirolimus-eluting stent; $S S=$ stainless steel; ST = Stent thrombosis; $T L F=$ target lesion failure;

$T L R=$ target lesion revascularisation; TVF = target vessel failure; TVR = target vessel revascularisation; $Z=$ zotarolimus; ZES = zotarolimus-eluting stent.

NCT01303640; $n=323$ ) with angiographic outcomes, showed that the cobalt-chromium polymer-free sirolimus-eluting stent (Cre8 ${ }^{\mathrm{TM}}$, Alvimedica, Istanbul, Turkey) offered reduced in-stent late lumen loss at 6 months when compared to a first-generation stainless-steel paclitaxel-eluting PP DES (TAXUS) $(0.14 \pm 0.36 \mathrm{~mm}$ versus $0.34 \pm 0.40 \mathrm{~mm}, p<0.0001$ for non-inferiority and superiority); however, marked difference in strut thickness is a notable confounder. ${ }^{21}$ When compared to BMSs in patients at high-risk of bleeding in the LEADERS FREE trial (NCT01623180), at 390 days the stainless-steel polymer-free BioFreedom biolimus-eluting stent was superior in the primary safety (composite of cardiac death, $\mathrm{Ml}$, or stent thrombosis) and efficacy (target lesion revascularisation) endpoints ( $9.4 \%$ versus $12.9 \%$ [HR $0.71,95 \% \mathrm{Cl} 0.56-0.91$, non-inferior $\mathrm{p}<0.001$, superior $\mathrm{p}=0.005$ ] and $5.1 \%$ versus $9.8 \%$ [HR $0.5095 \% \mathrm{Cl} 0.37-0.69, \mathrm{p}<0.001]$, respectively). ${ }^{42}$ There was no difference in rates of definite stent thrombosis between the groups (1.3\% versus $1.4 \%, \mathrm{HR} 0.93,95 \% \mathrm{Cl} 0.47-1.84, \mathrm{p}=0.84)$. These findings have recently been replicated in the LEADERS FREE II trial (NCT02843633). ${ }^{43}$

Although there have been no large RCTs comparing different types of polymer-free DES head-to-head, Chiarito and colleagues have recently published propensity-matched data obtained from the RUDI-FREE and ASTUTE registries assessing outcomes in those receiving two polymer-free DESs: the stainless-steel biolimus-eluting stent BioFreedom and the cobalt-chromium sirolimus-eluting stent Cre8. They found no significant differences in the primary endpoint of TLF at 12 months (4.0\% versus $4.2 \%$, HR $0.98,95 \% \mathrm{Cl} 0.57-1.70, \mathrm{p}=0.66$ ), nor definite stent thrombosis $(0.3 \%$ versus $0.7 \%, 0.49,95 \% \mathrm{Cl} 0.10-2.45, \mathrm{p}=0.31){ }^{44}$

\section{Comparison of eluted drugs}

A summary of RCTs that compared stents eluting different drugs is shown in Table 50,21,33,34,37-9,45-8 and Figure 2. Piccolo and colleagues performed a meta-analysis of the Resolute PP zotarolimus-eluting stent against PP everolimus-eluting stent (Promus/XIENCE), including five trials and 9,899 patients. ${ }^{49}$ There were no discernible differences between the zotarolimus-eluting stents and the everolimus-eluting stents in rates of the studied outcomes, including TVR (RR 1.06, 95\% Cl 0.90-1.24, $\mathrm{p}=0.50$ ) and definite or probable stent thrombosis (RR 1.26, 95\% Cl 0.86-1.85, $\mathrm{p}=0.24$ ). There was also no difference in definite or probable very late stent thrombosis (RR 1.06, $95 \%$ 0.53-2.11, $p=0.87$ ). Whilst these have not detected significant 


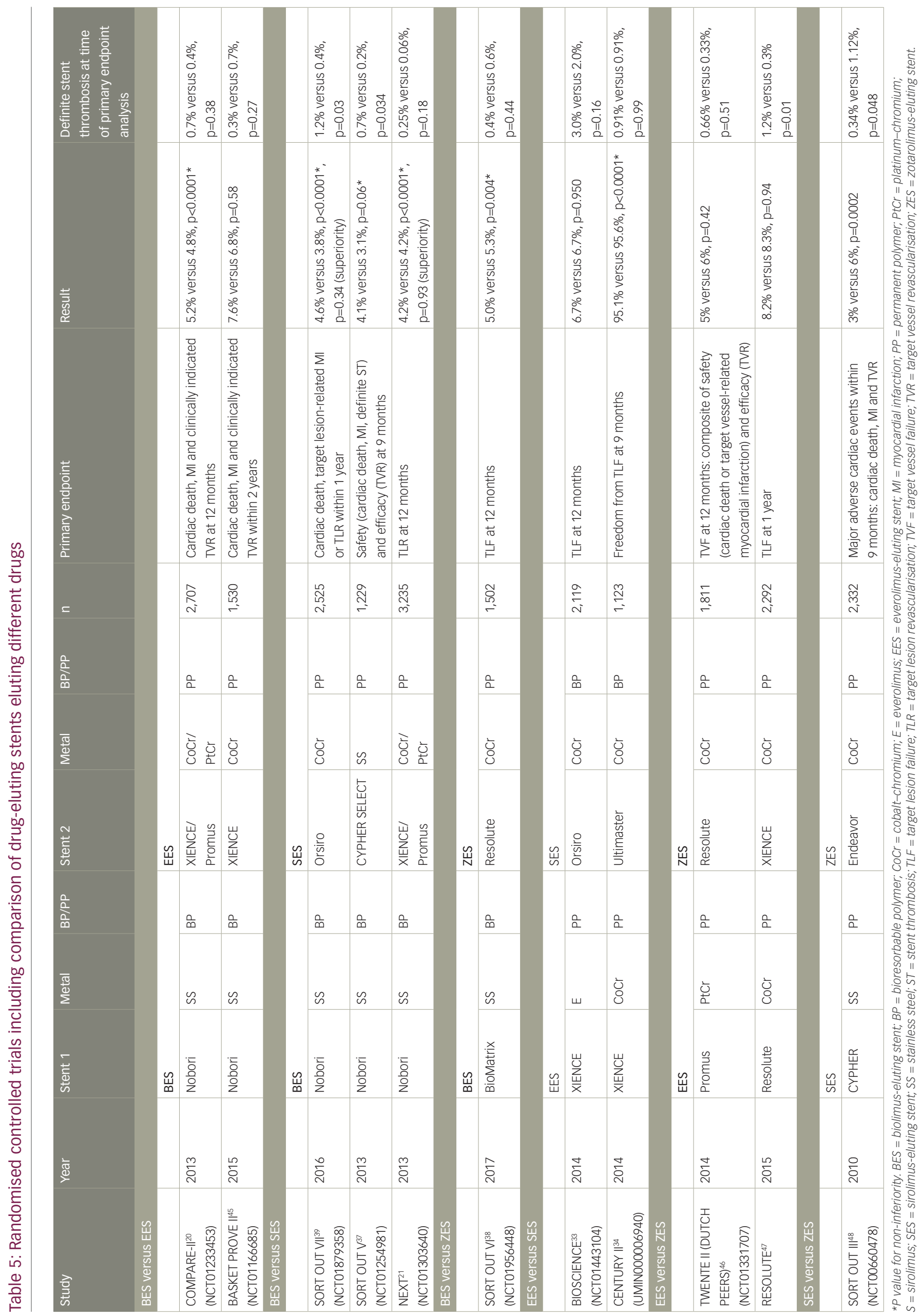


Figure 2: Pooled data of studies in Table 5 (where available)

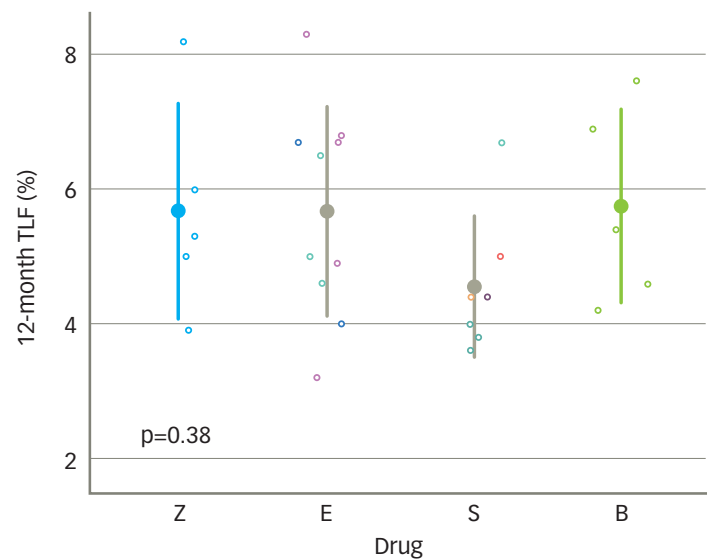

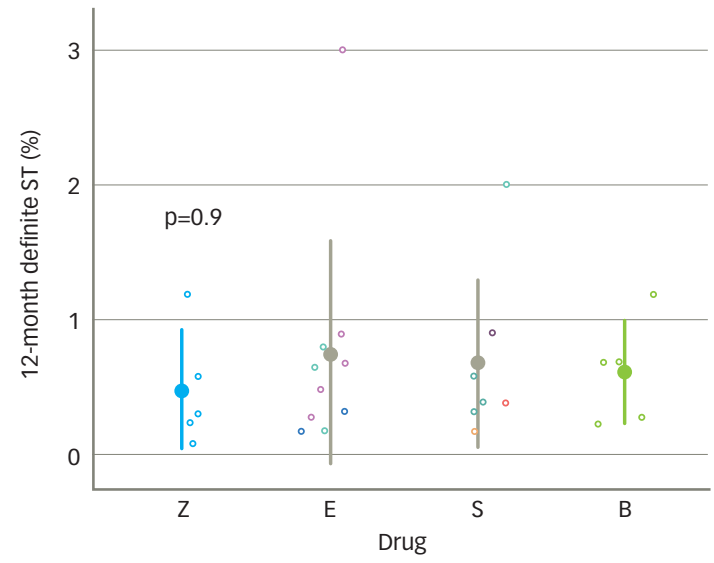

Stent

b BioMatrix

CYPHER SELECT

Nobori

Orsiro

$\phi$ Promus

Resolute

SYNERGY

U Ultimaster

XIENCE

A. Representative TLF; and B. stent thrombosis rates in drug-eluting stents eluting different drugs. Bars represent mean $\pm S D$ and $p$ values generated by one-way ANOVA are included for exploratory purposes only.

$B=$ biolimus; $E$ = everolimus; $S=$ sirolimus; $S D=$ standard deviation; $S T=$ stent thrombosis; $T L F=$ target lesion failure; $Z=$ zotarolimuS

differences in the studied primary endpoints, some differences in stent thrombosis rates have been observed; for example, the Nobori stainless-steel BP biolimus-eluting stent was associated with a significantly greater risk of stent thrombosis compared with the stainless-steel PP sirolimus-eluting stent CYPHER SELECTTM and the cobalt-chromium BP sirolimus-eluting stent Orsiro in the SORT-OUT V and VII trials, respectively (Table 5). ${ }^{37,39}$ However, it is difficult to discern whether this difference is due to the drug or other stent characteristics. Overall, one current-generation antiproliferative agent does not appear to have significantly different clinical properties to another.

\section{Limitations of clinical data}

Despite numerous clinical trials comparing DESs, these data have multiple limitations. Many trials are performed in selective groups of low-risk patients, often excluding elderly or unstable individuals with multiple comorbidities. Even 'all-comer' studies do not usually include all consecutive patients treated. Furthermore, it is usual for the statistical design of such studies to be based on proving non-inferiority over an established competitor, and although some pre-specify superiority analyses, the studies are not necessarily powered to detect this. The stents chosen for use in the active comparator arm of these studies often represent the older generations of DES or a BMS in situations where these have been regarded as standard-of-care. The primary endpoint of many trials is TLF, typically a composite of cardiac death, target vessel-related $\mathrm{MI}$, and clinically indicated target lesion revascularisation (TLR) at 6, 9 or 12 months and clinical follow-up to 5 years. However, the endpoints likely to differentiate DESs, for example stent thrombosis, are rare, making it very difficult to conduct an adequately powered study. Meta-analyses have helped to increase statistical power but have their own limitations. Additional difficulty in drawing conclusions comparing current DES performance arises from the fact that robust RCTs have not been performed to evaluate the very latest generation of stents in a 'family' (e.g. XIENCE Sierra, Promus PREMIER), and marketing authorisation has been granted on the basis of RCTs including the previous generations, combined with small-scale evaluation of the new design.

\section{How to choose a stent for a patient}

The availability of several DESs with similar data, whilst giving greater choice, may create confusion in selecting the optimal stent for a given patient. One may adopt a 'one size fits all' approach; however, there are subtle differences which may help to identify more suitable DESs for a particular patient or lesion type.

\section{A workhorse stent}

Data discussed above suggest that several current-generation DESS are perhaps comparable in both safety and efficacy. Any of these DESs can be used as a workhorse stent for the majority of patients. It would perhaps be ideal that at least two different DESS, with different characteristics and size matrix, are available in each cardiac catheterisation laboratory to make a more appropriate choice. The comparable safety and efficacy of DESs may also prompt different hospitals to largely determine their inventory of stents based on the cost of a DES. Depending on the volume of $\mathrm{PCl}$ cases in an institution, even a small difference in price may make significant impact on annual budget. It may also be an important factor in those healthcare systems where the patient or insurance has to pay.

\section{Stents for specific patient groups}

Most of the stent trials have generally shown no interaction between patient sub-groups or efficacy of one stent type over another. However, subtle differences have been observed. For patients with stent thrombosis elevation $\mathrm{Ml}$, perhaps DESs with $\mathrm{BP}$ are preferable. ${ }^{36,50}$ This has been further supported by the recently reported BIOSTEMI trial (NCT02579031) showing superiority of ultra-thin BP sirolimus-eluting stent Orsiro over DP everolimus-eluting stent XIENCE with respect to TLF at 1 year. ${ }^{51}$ For patients with high bleeding risk, BioFreedom or Resolute Onyx with 1-month dual antiplatelet therapy (DAPT) have the most supportive data. ${ }^{16}$

Patients with diabetes represent a challenging cohort. Most comparative trials of different DESs have shown no difference in effect of stent type between those with and without diabetes. In PLATINUM +, there was no difference in risk of the primary endpoint between those stented with PROMUS versus XIENCE (3.5\% versus 3.5\%, RR 1.00, 95\% $\mathrm{Cl} 0.62-1.60)$. However, in the sub-group with diabetes, XIENCE was favoured $(7.8 \%$ versus $3.0 \%$, RR $2.50,95 \% \mathrm{Cl} 1.16-5.38$, interaction $\mathrm{p}=0.05)$. This relationship, however, was not seen in the 5 -year follow-up data of the preceding PLATINUM trial with a similar design. ${ }^{25,52}$ 
Table 6: Currently ongoing or planned clinical trials comparing one drug-eluting stent with another

\begin{tabular}{|l|l|l|l|l|}
\hline Trial short title & $\begin{array}{l}\text { ClinicalTrials.gov } \\
\text { identifier }\end{array}$ & Summary of DESS involved & $\begin{array}{l}\text { Expected } \\
\text { recruitment }\end{array}$ & Primary focus \\
\hline ABILITY & NCT03399994 & AbluminuS DES+ (SES) versus EES & 165 & Angiographic \\
\hline BIOHEART II & NCT03284255 & Bioheart (BP-SES) versus XIENCE (PP-EES) & 430 & Angiographic \\
\hline CRE8-China-RCT & NCT02360423 & Cre8 (PF-SES) versus Resolute (PP-ZES) & 430 & Clinical outcomes \\
\hline CRYSTAL & NCT03423511 & Mistent II versuS XIENCE/Promus (PP-EES) & 1,300 & Clinical outcomes \\
\hline HOST-IDEA & NCT02601157 & Coroflex ISAR (PF-SES) versus Orsiro (BP-SES) & 2,152 & Angiographic \\
\hline MOrph RCT-1 & NCT03721614 & BioMime Morph (BP-SES) versus XIENCE (PP-EES) & 200 & Clinical outcomes \\
\hline PERFECT-II & NCT02133287 & AVI (arsenic trioxide DES) versuS Firebird2 (SES) & 2,000 & Clinical outcomes \\
\hline SORT OUT X & NCT03216733 & COMBO (SES + EPC) versus Orsiro (BP-SES) & 3,148 & Clinical outcomes \\
\hline SORT OUT XI & NCT03952273 & COMBO (SES + EPC) versus BioMatrix Alpha (BP-BES) & 3,140 & Clinical outcomes \\
\hline SUGAR & NCT03321032 & Cre8 (PF-SES) versus BioLinX (PP-ZES) & 1,164 & Clinical outcomes \\
\hline TARGET-AC & NCT02520180 & FirehawK (BP-SES) versus XIENCE (CoCr PP-EES) & 1,656 & Angiographic \\
\hline XLIMIT & NCT03745053 & XLIMUS (BP-SES) versus SYNERGY (BP-EES) & 180 & \\
\hline
\end{tabular}

Abluminus (Concept Medical, Tampa, FL, USA), AVI (Beijing AmsinoMed Medical Device Co., Ltd., Beijing, China), Bioheart (Bio-Heart, Shanghai, China), BioMime Morph (Meril Life, Gujarat, India), COMBO ${ }^{\circledast}$ dual therapy stent (OrbusNeich, Hong Kong, China), Coroflex ${ }^{\circledast}$ ISAR (B Braun, Sheffield, UK), Firebird2 ${ }^{\text {tm }}$ (MicroPort, Shanghai, China), Firehawk (MicroPort, Shanghai, China), Mistent (Micell Technologies, Durham, NC, USA), XLIMUS ${ }^{\oplus}$ (Cardionovum GmbH, Bonn, Germany).

$B E S=$ biolimus-eluting stent; $B P=$ bioresorbable polymer; $C O C r=$ cobalt-chromium; $D E S=$ drug-eluting stent; $E E S=$ everolimus-eluting stent; EPC = endothelial progenitor cells; $P F=$ polymer-free; $P P=$ permanent polymer; $S E S$ = sirolimus-eluting stent; ZES = zotarolimus-eluting stent.

The comparison of BP DESS versus PP DESs in patients with diabetes was recently examined by Bavishi et al., who included 5,190 patients from 11 RCTs in a meta-analysis, focusing on current-generation stents. ${ }^{53}$ After a mean follow-up of 2.7 years, there were no differences in a range of outcomes, including target lesion revascularisation (RR 1.02, 95\% $\mathrm{Cl} 0.85-1.24, \mathrm{p}=0.80$ ) and stent thrombosis (1.66\% versus $1.83 \%$, RR $0.84,95 \% \mathrm{Cl} 0.54-1.31, \mathrm{p}=0.45$ ) between the two stent types. There was no difference in this relationship between those patients with diabetes treated with and without insulin.

\section{Stents for specific lesion types}

Certain stents may perform better or at least may have been studied extensively for treating some complex lesions including left main stem, bifurcation lesions, chronic total occlusions, long lesions, and calcified lesions. For example, there have been many more dedicated trials with everolimus-eluting stents in unprotected left main disease or chronic total occlusions. Large left main stem with significant tapering after bifurcation may benefit from self-apposing Xposition S. Ostial lesions would require DESs with good radial strength and better visibility. Calcified or tortuous lesions will benefit from good radial strength and better deliverability. DESs with thinner struts and fewer connectors between stent rings are easier to deliver. Operator preference, usually based upon individual experience and familiarity with a given platform for a specific anatomy and technique chosen, should be valued as much as evidence from trials in stent selection.

\section{Is there any role for bare metal stents in the current era?}

DESS offered reduced in-stent restenosis rates when compared with BMSs, and this translates into clinical benefits on rates of revascularisation in particular. Use of DESs in individuals with a high bleeding risk has traditionally been avoided due to the requirement for longer DAPT with DES. However, with current-generation DESS with reduced strut thickness and better/no polymers, this has become less of an issue. BioFreedom and Onyx can be used in patients with high bleeding risk. Studies have also supported use of DESs during primary PCI for ST segment elevation MI. ${ }^{54}$ Patients receiving second-generation DESS for the treatment of saphenous vein graft disease also have lower rates of major adverse cardiovascular events and mortality, compared with those receiving BMSS. ${ }^{55}$ Finally, the cost of DESs has also substantially reduced in recent years, removing BMSs almost completely from the contemporary practice.

\section{On-going research and future directions}

A number of RCTs are underway, or are planned, to compare the performance of DESs, whether these be of new or existing designs (Table 6). There does not seem to be any major trial of a new platform or alloy. However, new polymers and polymer-free stents are being tested in these trials. Some studies are also exploring novel anti proliferative drugs, for example, arsenic trioxide rather than a 'limus' drug as an antiproliferative agent in the $A V{ }^{\circledR}$ stent (Beijing AmsinoMed Medical Device Co., Ltd., Beijing, China) in the PERFECT ॥ study (NCT02133287). Further studies on stents coated with an anti-CD34 antibody to capture circulating endothelial progenitor cells, development of which has been ongoing for some years, are also being conducted.

Although beyond the scope of this review, drug-eluting bioresorbable vascular scaffolds also remain a prominent area of development within PCl technology. Constructed of biodegradable polymer, they are designed to maintain radial strength and deliver an antiproliferative drug after implantation, but then to resorb altogether once all drug has been released. Benefits might include better long-term vessel dynamics and allowing subsequent bypass grafting at the site of PCl. ${ }^{56}$ Although outcomes, such as target lesion revascularisation, MI or death, appeared of similar incidence to DESS, rates of subacute stent thrombosis (1-30 days after implantation) were significantly greater, as was in-device late lumen loss. ${ }^{57}$ It remains to be seen whether technological development, for example constructing thinner strut bioresorbable vascular scaffolds, can enhance the risk-benefit profile of bioresorbable vascular scaffold to bring it back to clinical practice.

Many of these ongoing prospective studies also focus on angiographic outcomes or are non-inferiority of clinical outcomes, but are not powered to detect superiority of one stent type over another. Unfortunately, it is unlikely that data comparing stent types head-to-head in RCTs powered for superiority analyses will become available in the foreseeable future. 


\section{Summary}

The interventional cardiologist currently has a variety of stents available to treat obstructive coronary stenosis. DESs have been shown to be superior to BMSs in almost all patient and lesion types, and should be considered as default therapy in all $\mathrm{PCl}$ cases. A number of currently available DESs have comparable safety and efficacy. DESS made of cobalt-chromium or platinum-chromium are generally preferable as they allow stents with thinner struts. It remains difficult to elucidate significant differences between the eluted 'limus' type drugs, and for clinical purposes, it seems likely that these drugs are of comparable safety and efficacy. Whilst BP DESs have theoretical advantages over PP DESS, at present these do not appear to be clinically significant in the short to medium term. This might be because current-generation PP DESs have thinner struts and exploit more biocompatible polymers than previous generations. However, the ultra-thin BP sirolimus-eluting stent, Orsiro, has shown favourable results in patients with stent thrombosis segment elevation MI. In patients with high bleeding risk, Onyx or BioFreedom DESs should be considered with 4 weeks of DAPT. Clinicians should be aware of the properties of different stent types, as well as supporting clinical data when making decisions regarding use of specific devices, and match these to the individual scenarios to provide the best stent type for a particular patient and lesion.
1. Iqbal J, Serruys PW, Taggart DP. Optimal revascularization for complex coronary artery disease. Nat Rev Cardiol. 2013;10:635-47

2. GlobeNewswire. Coronary stents market worth around $\$ 16.88$ billion by 2025. 2019. Available at: www.globenewswire.com/ news-release/2019/06/04/1864071/0/en/Coronary-StentsMarket-Worth-Around-US-16-88-bn-by-2025.html (accessed 18 March 2020

3. Cardiovascular Business. CV stents market expected to exceed \$13B by 2025. 2020. Available at: www.cardiovascularbusiness. $\mathrm{com} /$ topics/coronary-intervention-surgery/cv-stents-marketcom/topics/coronary-intervention-surgery/cv-stents-m

4. MedPage Today. East meets West: Chinese, Indian stents aim for global market. 2018. Available at: www.medpagetoday.com/ cardiology/pci/76144 (accessed 18 March 2020).

5. Gruntzig A. Transluminal dilatation of coronary-artery stenosis. Lancet. 1978;1:263.

6. Iqbal J, Gunn J, Serruys PW. Coronary stents: historical development, current status and future directions. Br Med Bull. 2013;106:193-211.

7. Sigwart U, Puel J, Mirkovitch V, et al. Intravascular stents to prevent occlusion and restenosis after transluminal angioplasty. N Engl J Med. 1987:316:701-6.

8. Serruys PW, Strauss BH, Beatt KJ, et al. Angiographic follow-up after placement of a self-expanding coronary-artery stent. N Engl J Med. 1991;324:13-7.

9. de Feyter PJ, de Jaegere PP, Serruys PW. Incidence, predictors, and management of acute coronary occlusion after coronary angioplasty. Am Heart J. 1994:127:643-51.

10. Fischman DL, Leon MB, Baim DS, et al. A randomized comparison of coronary-stent placement and balloon angioplasty in the treatment of coronary artery disease. Stent Restenosis Study Investigators. N Eng/ J Med. 1994;331:496-501.

11. Morice MC, Serruys PW, Sousa JE, et al. A randomized comparison of a sirolimus-eluting stent with a standard stent for coronary revascularization. N Eng/ J Med. 2002;346:1773-80.

12. Stone GW, Ellis SG, Cox DA, et al. A polymer-based, paclitaxel-eluting stent in patients with coronary artery disease. N Engl J Med 2004:350:221-31.

13. Lasala JM, Stone GW, Dawkins KD, et al. An overview of the TAXUS Express, paclitaxel-eluting stent clinical trial program. J Interv Cardiol. 2006:19:422-31.

14. Lagerqvist $B$, Carlsson J. Frobert $O$, et al. Stent thrombosis in Sweden: a report from the Swedish coronary Angiography and Angioplasty Registry. Circ Cardiovasc Interv. 2009:2:401-8.

15. Laskey WK, Yancy CW, Maisel WH. Thrombosis in coronary drug-eluting stents: report from the meeting of the Circulatory System Medical Devices Advisory Panel of the Food and Drug Administration Center for Devices and Radiologic Health, December 7-8, 2006. Circulation. 2007;115:2352-7.

16. Price MJ, Shlofmitz RA, Spriggs DJ, et al. Safety and efficacy of the next generation Resolute Onyx zotarolimus-eluting stent: Primary outcome of the RESOLUTE ONYX core trial. Catheter Cardiovasc Interv. 2018:92:253-9.

17. Popma JJ, Mauri L, O'Shaughnessy C, et al. Frequency and clinical consequences associated with sidebranch occlusion during stent implantation using zotarolimus-eluting and paclitaxel-eluting coronary stents. Circ Cardiovasc Interv. paclitaxel-eluing $2009: 2: 133-9$

18. Iantorno M, Lipinski MJ, Garcia-Garcia HM, et al. Meta-analysis of the impact of strut thickness on outcomes in patients with drug-eluting stents in a coronary artery. Am I Cardiol. 2018;122:1652-60.

19. Iqbal J, Verheye S, Abizaid A, et al. DESyne novolimus-eluting coronary stent is superior to Endeavor zotarolimus-eluting coronary stent at five-year follow-up: final results of the multicentre EXCELLA II randomised controlled trial. Eurolntervention. 2016;12:e1336-42.

20. Smits $\mathrm{PC}$, Hofma S, Togni M, et al. Abluminal biodegradable polymer biolimus-eluting stent versus durable polyme everolimus-eluting stent (COMPARE II): a randomised, controlled, non-inferiority trial Lancet 2013:381:651-60.

1. Natsuaki M, Kozuma K Morimoto T. patsuaki, Kozzak, Mormoto polymer biolimus-eluting stent versus durable polym everolimus-eluting stent: a randomized, controlled,

22. Natsuaki M, Kozuma K, Morimoto T, et al. Five-year outcome of a randomised trial comparing second-generation drug-eluting stents using either biodegradable polymer o durable polymer: the NOBORI biolimus-eluting versus XIENCE/PROMUS everolimus-eluting stent trial (NEXT) Eurolntervention. 2018;14:815-8.
23. Maeng $M$, Christiansen $E H$, Raungaard $B$, et al. Everolimus-eluting versus biolimus-eluting stents with biodegradable polymers in unselected patients undergoing percutaneous coronary intervention: a randomized noninferiority trial with 1-year follow-up (SORT OUT VIII Trial). JACC Cardiovasc Interv. 2019;12:624-33.

24. Puricel S, Arroyo D, Corpataux N, et al. Comparison of everolimus- and biolimus-eluting coronary stents with everolimus-eluting bioresorbable vascular scaffolds. J Am Coll Cardiol. 2015;65:791-801.

25. Stone GW, Teirstein PS, Meredith IT, et al. A prospective, randomized evaluation of a novel everolimus-eluting coronary stent: the PLATINUM (a Prospective, Randomized Multicenter Trial to Assess an Everolimus-Eluting Coronary Stent System [PROMUS Element] for the Treatment of Up to Two de Novo Coronary Artery Lesions) trial. J Am Coll Cardiol. 2011;57:1700-8

26. Fajadet J, Neumann FJ, Hildick-Smith D, et al. Twelve-month results of a prospective, multicentre trial to assess the everolimus-eluting coronary stent system (PROMU Element): the PLATINUM PLUS all-comers randomised trial. Eurolntervention. 2017;12:1595-604.

27. Fujii K, Carlier SG, Mintz GS, et al. Stent underexpansion and residual reference segment stenosis are related to stent thrombosis after sirolimus-eluting stent implantation: an intravascular ultrasound study. J Am Coll Cardiol. 2005:45:995-8.

28. Pellegrini D, Cortese B. Focus on STENTYS ${ }^{\oplus}$ Xposition S SelfApposing ${ }^{\circledR}$ stent: a review of available literature. Future Cardio. 2019;15:145-59.

29. Bangalore S, Toklu B, Patel N, et al. Newer-generation ultrathin strut drug-eluting stents versus older second-generation thicker strut drug-eluting stents for coronary artery disease. Circulation. 2018;138:2216-26.

30. Kandzari DE, Mauri L, Koolen JJ, et al. Ultrathin, bioresorbable polymer sirolimus-eluting stents versus thin, durable polyme everolimus-eluting stents in patients undergoing coronary revascularisation (BIOFLOW V): a randomised trial. Lancet. 2017;390:1843-52

31. von Birgelen C, Zocca P, Buiten RA, et al. Thin composite wire strut, durable polymer-coated (Resolute Onyx) versus ultrathin cobalt-chromium strut, bioresorbable polymer-coated (Orsiro) cobalt-chromium strut, bioresorbable polymer-coated (Orsiro)
drug-eluting stents in allcomers with coronary artery disease drug-eluting stents in allcomers with coronary artery
(BIONYX): an international, single-blind, randomised non-inferiority trial. Lancet. 2018:392:1235-45.

32. von Birgelen $C, K o k M M$, van der Heijden $L C$, et al. Very thin strut biodegradable polymer everolimus-eluting an sirolimus-eluting stents versus durable polyme zotarolimus-eluting stents in allcomers with coronary artery disease (BIO-RESORT): a three-arm, randomised, non-inferiority trial. Lancet. 2016;388:2607-17.

33. Pilgrim T, Heg D, Roffi M, et al. Ultrathin strut biodegradable polymer sirolimus-eluting stent versus durable polymer everolimus-eluting stent for percutaneous coronary revascularisation (BIOSCIENCE): a randomised, single-blind, non-inferiority trial. Lancet. 2014;384:2111-22.

34. Saito S, Valdes-Chavarri M, Richardt G, et al. A randomized, prospective, intercontinental evaluation of a bioresorbable polymer sirolimus-eluting coronary stent system: the CENTURY polymer sirolimus-eluting coronary stent system: the CENTURY
II (Clinical Evaluation of New Terumo Drug-Eluting Coronary $\|$ (Clinical Evaluation of New Terumo Drug-Eluting Coronary
Stent System in the Treatment of Patients with Coronary Artery Stent System in the Treatment of Patients W
Disease) trial. Eur Heart I. 2014:35:2021-31.

35. Kereiakes DJ, Meredith IT, Windecker S, et al. Efficacy and safety of a novel bioabsorbable polymer-coated, everolimus-eluting coronary stent: the EVOLVE II Randomized Trial. Circ Cardiovasc Interv. 2015;8:e002372.

36. Windecker S, Serruys PW, Wandel S, et al. Biolimus-eluting stent with biodegradable polymer versus sirolimus-eluting stent with durable polymer for coronary revascularisation (LEADERS): a randomised non-inferiority trial. Lancet. 2008:372:1163-73.

37. Christiansen EH, Jensen LO, Thayssen P, et al. Biolimus-eluting biodegradable polymer-coated stent versus durable polymer-coated sirolimus-eluting stent in unselected patients receiving percutaneous coronary intervention (SORT OUT V): a randomised non-inferiority trial. Lancet. 2013:381:661-9.

38. Raungaard B, Christiansen EH, Botker HE, et al. Comparison of durable-polymer zotarolimus-eluting and biodegradable-polymer biolimus-eluting coronary stents in patients with coronary artery disease: 3 -year clinical outcomes in the randomized SORT OUT VI Trial. JACC Cardiovasc Interv. 2017;10:255-64.
39. Jensen LO, Thayssen P, Maeng M, et al. Randomized comparison of a biodegradable polymer ultrathin strut sirolimus-eluting stent with a biodegradable polymer biolimus-eluting stent in patients treated with percutaneous coronary intervention: the SORT OUT VII Trial. Circ Cardiovas Interv. 2016;9:e003610.

40. El-Hayek G, Bangalore S, Casso Dominguez A, et al. Meta-analysis of randomized clinical trials comparing biodegradable polymer drug-eluting stent to second-generation durable polymer drug-eluting stents. JACC Cardiovasc Interv. 2017;10:462-73

41. Kobayashi T, Sotomi Y, Suzuki S, et al. Five-year clinical efficacy and safety of contemporary thin-strut biodegradable polymer versus durable polymer drug-eluting stents: a systematic versus durable polymer drug-eluting stents: a systematic
review and meta-analysis of 9 randomized controlled trials review and meta-analysis of 9 randomiz
Cardiovasc Interv Ther. 2020;35:250-8.

42. Urban P, Meredith IT, Abizaid A, et al. Polymer-free drug-coated coronary stents in patients at high bleeding risk. N Eng/ J Med. 2015;373:2038-47.

43. Kumbhani D. Prospective randomized comparison of the BioFreedom biolimus A9 drug-coated stent versus the Gazelle bare-metal stent in patients at high bleeding risk II - LEADERS FREE II. 2018. Available at: www.acc.org/latest-in-cardiology/ clinical-trials/2018/09/20/20/50/leaders-free-ii (accessed 18 March 2020)

44. Chiarito M, Sardella G, Colombo A, et al. Safety and efficacy of polymer-free drug-eluting stents. Circ Cardiovasc Interv. 2019;12:e007311.

45. Kaiser $\mathrm{C}$, Galatius $\mathrm{S}$, Jeger R, et al. Long-term efficacy and safety of biodegradable-polymer biolimus-eluting stents: main results of the Basel Stent Kosten-Effektivitats Trial-PROspective Validation Examination II (BASKET-PROVE II), a randomized, controlled noninferiority 2-year outcome trial. Circulation. 2015;131:74-8.

46. von Birgelen C, Sen H, Lam MK, et al. Third-generation zotarolimus-eluting and everolimus-eluting stents in all-comer patients requiring a percutaneous coronary intervention (DUTCH PEERS): a randomised, single-blind, multicentre, non-inferiority trial. Lancet. 2014:383:413-23.

47. Iqbal J, Serruys PW, Silber S, et al. Comparison of zotarolimus- and everolimus-eluting coronary stents: final 5 -year report of the resolute all-comers trial. Circ Cardiovasc Interv. 2015:8:e002230.

48. Rasmussen K, Maeng M, Kaltoft A, et al. Efficacy and safety of zotarolimus-eluting and sirolimus-eluting coronary stents in routine clinical care (SORT OUT III): a randomised controlled superiority trial. Lancet. 2010;375:1090-9.

49. Piccolo R, Stefanini GG, Franzone A, et al. Safety and efficacy of resolute zotarolimus-eluting stents compared with everolimus-eluting stents: a meta-analysis. Circ Cardiovasc Interv. 2015;8:e002223.

50. Zhang YJ, Iqbal J, Windecker S, et al. Biolimus-eluting stent with biodegradable polymer improves clinical outcomes in patients with acute myocardial infarction. Heart. 2015;101:271-8.

51. Iglesias JF, Muller O, Heg D, et al. Biodegradable polymer sirolimus-eluting stents versus durable polymer everolimus-eluting stents in patients with ST-segment elevation myocardial infarction (BIOSTEMI): a single-blind, prospective, myocardial infarction (BIOSTEMI). a single-blind, prospective

52. Kelly CR, Teirstein PS, Meredith IT, et al. Long-term safety and efficacy of platinum chromium everolimus-eluting stents in coronary artery disease: 5-year results from the PLATINUM trial. JACC Cardiovasc Interv. 2017:10:2392-400.

53. Bavishi C, Chugh Y, Kimura T, et al. Biodegradable polymer drug-eluting stent versus contemporary durable polymer drug-eluting stents in patients with diabetes: a meta-analysis of randomized controlled trials. Eur Heart I Qual Care Clin Outcomes. 2020;6:81-8.

54. Lavi S, I qbal J, Cairns JA, et al. Bare metal versus drug eluting stents for ST-segment elevation myocardial infarction in the TOTAL trial. Int J Cardiol. 2017;248:120-3.

55. Iqbal J, Kwok CS, Kontopantelis E, et al. Choice of stent for percutaneous coronary intervention of saphenous vein grafts Circ Cardiovasc Interv. 2017:10:e004457.

56. Iqbal J, Onuma Y, Ormiston J, et al. Bioresorbable scaffolds: rationale, current status, challenges, and future. Eur Heart 2014;35:765-76.

57. Cassese S, Byrne RA, Ndrepepa G, et al. Everolimus-eluting bioresorbable vascular scaffolds versus everolimus-eluting metallic stents: a meta-analysis of randomised controlled trials. Lancet. 2016;387:537-44 